\title{
Novel Phytoconstituents of an Aqueous Pod Extract of Prosopis Cineraria (L.) Druce Attenuate Atherosclerotic Plaque and Hypercholesterolemia in Rabbits
}

Heera Ram ( $\nabla$ hr.zo@jnvu.edu.in )

Jai Narain Vyas University https://orcid.org/0000-0001-6743-1321

Noopur Jaipal

Jai Narain Vyas University

Pramod Kumar

Jai Narain Vyas University

Jaykaran Charan

All India Institute of Medical Sciences Jodphur

Priya Kashyap

Guru Gobind Singh Indraprastha University

Suresh Kumar

Guru Gobind Singh Indraprastha University

Garima Singh

Mizoram University Pachhunga University College

Anshuman Dixit

Institute of Life Sciences

Abeer Hashem

King Saud University College of Science

Abdulaziz A Alqarawi

King Saud University College of Science

Elsayed Fathi Abd_Allah

King Saud University College of Science

Bhim Pratap Singh

National Institute of Food Technology and Management

\section{Research}

Keywords: HMG-CoA reductase, Hypercholesterolemia, Phytoconstituents, lipid profile, antioxidants, Prosopis cineraria, atherosclerosis 
Posted Date: September 2nd, 2020

DOI: https://doi.org/10.21203/rs.3.rs-56652/v1

License: (c) (i) This work is licensed under a Creative Commons Attribution 4.0 International License. Read Full License 


\section{Abstract}

Background and objectives: The pod of Prosopis cineraria traditionally used in several ailments and key component of traditional food recipe of the Panchkuta of western Rajasthan, India. The current study was targeted to assess ability of phytoconstituents of aqueous pod extract of Prosopis cineraria to inhibit HMG-CoA reductase activity and regress atherosclerotic plaque were investigated in in-vitro, in-vivo, and in-silico studies.

Material and Methods: LCMS, GCMS, and FTIR analysis were used to characterize the phytoconstituents of the test extract. Accordingly, the in-vitro, in-vivo and in-silico assessments were performed by following the standard methods.

Results: The phytochemical results shown the presence of cloprostenol, cinecromen, and dirithromycin as leading compounds. Accordingly, in-vivo assay of test extract shown HMG-CoA inhibition activity by 78.1 $\%\left(\mathrm{IC}_{50}\right.$ was $\left.0.03 \mu \mathrm{g} / \mathrm{ml}\right)$. Hypercholesterolemia was induced in rabbits through oral supplementation of a high fat diet (21\% fat) with cholesterol powder supplementation. Administration of the test extract caused significant $(P \leq 0.001)$ improvement in the lipid profile and antioxidant levels in the test rabbits, relative to the hypercholesterolemic control rabbits. Subsequently, the reductions in the atherosclerotic plaque and improvement in lumen volume were pointedly observed in the treated groups. In-silico analyses of molecular docking and ADMET revealed significant interactions and druggability profile.

Conclusion: It can be stated that the phytoconstituents of aqueous pod extract of Prosopis cineraria have the capacity to inhibit HMG-CoA reductase and regress the atherosclerotic plaque which may be beneficial to the treatment of hypercholesterolemia.

\section{Introduction}

The enzyme, 3-hydroxy-3-methylglutary-coenzyme A (HMG-CoA) reductase plays a key role in regulating the cholesterol biosynthetic pathway. Inhibition of HMG-CoA reductase activity will reduce cholesterol synthesis and thus increase hepatic uptake of low density lipids (LDL) by modulation of LDL receptors[1]. The present use of statins in humans as a HMG-CoA reductase inhibitor is associated with a number of adverse effects, such as hepatoxicity, myopathy, gastrointestinal upset, cataracts, rhabdomyolysis, and an increased risk of diabetes[2]. Therefore, the present study evaluated dietary constituents that represent key components utilized in folk medicine in India [3,4]. Herbal formulations based complementary medicine are receiving greater attention and acceptance in India and a growing number of other countries, due to results of evidence-based studies of their safety and effectiveness. Several herbal formulations have been reported in the literature for the treatment of hypercholesterolemia and diabetes that were used historically by local populations of people based on traditional knowledge passed down from generation to generation [4-7]. Dietary supplements of antioxidant formulations are also available to ameliorate risk factors associated with hypercholesterolemia[8-10]. Several studies have indicated that the use of plant-derived antioxidant formulations are more preferred than synthetic drugs to reduce 
oxidative injury [11]. Several phytoconstituents have also been reported to possess significant antioxidant properties $[12,13]$. Phytoconstituents have been reported to be "a revived medicine" and "a foundation of dietetic antioxidants" $[14,15]$. Local people in rural areas have used plant-based products based on traditional knowledge to cure a variety of diseases. Given this background, the present study evaluated the medicinal properties of Prosopis cineraria, a desert plant found in western Rajasthan, India. It can survive the adverse stress brought on by insufficient water availability. P. cineraria is a member of the Leguminosae and is used by local people to treat various ailments and as a nutritional supplement[16, 17]. Unripe pods of $P$. cineraria, locally known as 'Sangari', are stored after drying and used as a food supplement. Dried pods of $P$. cineraria are ingested by the local people at the first sign of any dietary problems or other ailments [18]. In our study, the anti-atherosclerotic, anti-hypercholesterolemic, and antioxidant properties of an aqueous extract of $P$. cineraria pods were evaluated in vitro, in silico and in vivo. The phytochemical constituents present in the extract were also identified to determine which phytoconstituents might be responsible for its medicinal properties.

\section{Material And Methods}

\section{Pod procurement, authentication, and extraction method}

Dried pods of Prosopis cineraria (L.) Druce were obtained from a local provisional store and their taxonomic identity was confirmed by a botanical expert using an old herbarium voucher. The dried pods were ground in a mixer, macerated after boiling in hot water, and then vacuum dried. The resulting sticky extract was stored under desiccated conditions. Atorvastatin, a type of statin, was purchased from a local medical store and used as a positive control. All chemicals and reagents were purchased from local suppliers, Jodhpur (Rajasthan), India.

\section{Phytochemical analysis of the extract}

A phytochemical analysis and identification of the small molecular weight compounds in the extract was conducted by LCMS, GCMS, and FTIR analysis. The small molecular weight phytoconstituents were identified using METLIN software which identified the masses of the obtained peaks and identified them based on the monoisotopic mass of standard compounds using $\mathrm{M}$ and $\mathrm{M}+\mathrm{H}$ ions in QTOF mass hunter software. The default series for mass identification used a value greater than $100 \mathrm{~m} / \mathrm{z}$ ratio.

\section{LC/MS chemical analysis}

A metabolomic analysis based on LC-MS was conducted to characterize the chemical fingerprint of the plant extract. Several mobile phase sequences were analysed in the analysis to obtain a comprehensive characterization of chromatographic peaks [19].

\section{Gas chromatography with tandem mass spectrometry (GC-MS/MS) analysis}

GC-MS analysis of an ethanol pod extract of $P$. cineraria was conducted using a standard protocol. The sample was injected into a gas chromatograph interfaced with a mass spectrometer (GC-MS) [20]. The 
LC-MS/MS and GC-MS/MS was used to identify the phytoconstituents in the extract based on the separation and isolation of small molecular weight compounds based on their molecular weight, retention time, as well as other chromatographic techniques[21].

\section{FTIR analysis}

An FTIR Spectrophotometer (Bruker Co., Germany) equipped with a standard detector and a germanium beam splitter, interfaced with a computer and analytical software, was utilized for the analysis. $\mathrm{The} \mathrm{KBr}$ pellet technique was used to obtain a spectrum in the mid IR region of $400-4000 \mathrm{~cm}^{1}$. The spectrum was characterized using the attenuated Total Reflectance (ATR) technique [22].

\section{In-vitro assays}

\section{HMG -CoA reductase activity}

In-vitro inhibition of HMG CoA reductase activity by the plant extract was performed using an HMG-CoA reductase assay kit (Sigma-Aldrich), based on the measurement of absorbance in a spectrophotometer. The assays utilized increasing concentrations of the pod extract $(1.56 \mu \mathrm{g} / \mathrm{ml}, 3.13 \mu \mathrm{g} / \mathrm{ml}, 6.25 \mu \mathrm{g} / \mathrm{ml}$, $12.50 \mu \mathrm{g} / \mathrm{ml}$ and $25 \mu \mathrm{g} / \mathrm{ml}$ ) and pravastatin as a positive control. The concentration of the HMG-CoA reductase enzyme solutions ranged between $0.50-0.70 \mathrm{mg} / \mathrm{ml}$. The different concentrations of the aqueous extract were mixed with a reaction mixture containing NADPH, HMG-CoA substrate, and HMGR. Pravastatin (Sigma Aldrich co.) was used as a positive control and distilled water served as a negative control $[20,23]$.

\section{Antioxidants assays}

The in-vitro antioxidant potential of the pod extract was evaluated using both ABTS and FRAP assays [24]. The FRAP reagent was prepared freshly at a ratio of 10:1:1 by mixing $300 \mathrm{mM}$ acetate buffer ( $\mathrm{pH}$ 3.6), $10 \mathrm{mM}$ of 2,4,6-tripyridyl-s-triazine (TPTZ), and $20 \mathrm{mM}$ of $\mathrm{FeCl} 3 \cdot 6 \mathrm{H} 2 \mathrm{O}$. The assays were carried out in triplicate in a 96 -well plate by mixing $20 \mu \mathrm{l}$ of plant extract at different concentrations with $180 \mu$ l of FRAP reagent. The reaction was incubated at $37^{\circ} \mathrm{C}$ in the dark for 30 minutes and absorbance was measured at $593 \mathrm{~nm}$. The antioxidant capacity was calculated as ferrous equivalents using a standard curve generated with $\mathrm{FeSO}_{4}$.

The ABTS reagent was prepared by mixing a $7 \mathrm{mM}$ ABTS solution with $2.4 \mathrm{mM}$ potassium persulfate. The reagent was stored in the dark for 16-24 hours to stabilize it prior to use. A working solution was prepared by diluting the reagent with ethanol to obtain an absorbance of 0.70 at $734 \mathrm{~nm}$ at $37^{\circ} \mathrm{C}$. Subsequently, $10 \mu$ l of the plant extract was mixed with $190 \mu$ l of diluted ABTS reagent in a 96-well plate. Trolox was used as a positive standard to measure the relative percentage scavenging activity of the aqueous pod extract of $P$. cineraria.

\section{In-vivo Study}




\section{Induction of hypercholesterolemia and experimental groups}

A rabbit (New Zealand white males) animal models were selected for use in the study having an approximate weight of $1.5 \pm 0.5 \mathrm{~kg}, 6-9$ months in age and were deemed healthy after an inspection by a veterinarian. The animals were kept under standard environmental conditions with a 12-hour light/dark cycle. The rabbits were used for experimentation after ten days of acclimatization to the laboratory conditions.

Hypercholesterolemia was induced by oral administration of $500 \mathrm{~g}$ of cholesterol powder mixed with $5 \mathrm{ml}$ of coconut oil for 15 days, along with a high fat diet(21\% fat) [25].

Animals were divided into four groups, with each group containing five rabbits. The experiment ran for 60 days. The experimental groups were as follows:

Group 1: Vehicle Control, treated with only distilled water for 60 days.

Group 2: Hypercholesterolemic control, diseased animal model.

Group 3: Treatment with aqueous pod extract of Prosopis cineraria (500mg/kg for 45 days, oral).

Group 4: Treatment with atorvastatin $(0.25 \mathrm{mg} / \mathrm{kg})$.

\section{Biochemical analyses}

Blood was collected from animals in each of the treatment groups and serum was separated from blood by centrifugation using a standard protocol and stored at $-20^{\circ} \mathrm{C}$. After thawing, assessments were made of total cholesterol [26], triglyceride [27], HDL - cholesterol [28], glucose [29], and total protein[30]. All measurements were conducted by following the standard methods. The lipid profile and atherogenic indices were calculated using Friedewald's formula[31,32].

\section{Serum antioxidant assay}

The antioxidant capacity of the serum was evaluated by measuring catalase, SOD (superoxide dismutase)[33], GSH[34], lipid peroxidation (LPO)[35], and total antioxidant activity[36]. Thiobarbituric acid reactive substances (TBARS) were examined as an index of lipid peroxidation.

\section{Histopathology and planimetric analysis}

The aortas of the four different experimental groups were obtained from autopsied animals and processed for histopathological examination. The aortas were fixed in $10 \%$ formalin, processed for embedding and sectioning. Tissue sections were mounted on glass slides, stained, and then covered with a cover slip for evaluation under a microscope. Planimetric studies of the aorta wall, lumen volume, and atherosclerotic plaque were conducted using a Camera Lucida [25]. 


\section{Molecular docking}

\section{Ligand preparation}

A set of 16 molecules (Table 1) were docked onto human HMG-COA reductase receptors (PDB ID:1HWK). The molecules in structure data format (sdf) were downloaded from Pubchem using their structure CIDs. The geometry of the molecules was optimized using OPLS2005 force field and low energy conformers generated in the LigPrep module of Schrodinger[37]. The generated conformers were then used in the molecular docking studies.

\section{Receptor preparation}

The three-dimensional crystal structure of human HMG-COA reductase was obtained from a protein data bank and resolved using X-ray diffraction method (PDB ID: 1HWK). The protein structure was prepared in the "PrepWiz" module of Schrodinger. Hydrogens were added, bond orders were assigned, and proper ionization states were assigned during pre-processing. The structure was optimized using restrained minimization by OPLS2005 force field. The prepared structure was used in the docking studies.

\section{Grid generation and docking}

Co-crystallized ligand was used as a reference to define the receptor binding sites and a receptor grid was generated around the centroid of the co-crystallized ligand (Atorvastatin). The binding pocket residues at MET657, SER661, VAL683, ARG590, SER684, CYS688, ASN686, ASP690, LYS691, and LYS692 were used for grid generation. The docking was done using the Glide module of Schrodinger in a standard precision (SP) mode. The molecules were ranked after docking on the basis of their glide g-score which utilizes different parameters such as lipophilic terms, hydrogen bond terms, metal ligand interaction, Vander Waals interaction, solvation, $\pi-\pi$, and cation $-\pi$ interactions to calculate the glide score[38].

\section{ADMET and BBB studies}

Analysis of absorption, distribution, metabolism, excretion, and toxicity (ADMET) properties of the identified compounds utilizing by Drulito online software. The violation of ideal drug properties such as molecular weight $(\mathrm{MW})$, partition coefficient $(\log \mathrm{P})$, octanol-water partition coefficient (AlogP), H-bond donor (HBD), H-bond acceptor (HBA), total polar surface area (TPSA), nHB (number of Hydrogen Bonds), and the number of acidic groups present were evaluated for violation of the Lipinski rule of five and for the ability of the identified compounds to pass through blood brain barrier (BBB) filters.

\section{Statistical Analysis}

Results of the biochemical assessments, organ weights, and planimetric studies are expressed as a mean \pm standard error of the mean (SEM). Significant statistical differences were determined by one-way ANOVA and student 't'test[39]. 


\section{Results}

\section{In-vitro investigations}

\section{HMG-CoA reductase inhibition}

Increasing concentrations of the pod extract and a standard drug (Pravastatin) were evaluated for their ability to inhibit HMG-CoA reductase. The $\mathrm{IC}_{50}$ of the pod extract was $\mathrm{IC}_{50}=0.03 \mu \mathrm{g} / \mathrm{ml}$ and performed $78.1 \%$ inhibition of HMG-CoA reductase (Figure 1B), while the standard drug inhibited $93.1 \%$ of HMG-CoA reductase activity at $\mathrm{IC}_{50}=0.02 \mu \mathrm{M}($ Figure $1 \mathrm{~A})$.

\section{Antioxidant Assays of extract}

A standard curve was generated using ferrous sulphate to determine $\mathrm{Fe}^{2+}$ equivalents for the different concentrations of pod extract as a measure of antioxidant potential. The absorbance value of the different concentrations of pod extract were converted into FRAP equivalents using the slope of the standard curve. Results revealed that the antioxidant activity of aqueous pod extract was concentration dependent over the range of $12.5 \mathrm{mg} / \mathrm{mL}$ to $200 \mathrm{mg} / \mathrm{mL}$. The maximum value of $\mathrm{Fe}^{2+}$ equivalent, $217.71 \pm$ $0.042 \mathrm{~mol} \mathrm{mFe}{ }^{2+} \mathrm{E} / \mathrm{g}$ was obtained at $200 \mathrm{mg} / \mathrm{mL}$ of aqueous pod extract (Figure $2 \mathrm{~A}$ ). The TEAC antioxidant assay using ABTS also indicated that the antioxidant scavenging activity of the pod extract as measured by trolox equivalents was also concentration dependent. The absorbance values obtained with different concentrations of pod extract were used to calculate percentage scavenging using the equation: 1.0- sample absorbance/control absorbance) multiplied by 100 . Results indicated that the maximum percentage of scavenging activity (34\%) was obtained at t $200 \mu \mathrm{g} / \mathrm{mL}$ pod extract (Figure $2 \mathrm{~B}$ ).

\section{In-vivo Studies}

\section{Lipid profile and atherogenic indices}

Lipid profile parameters (total cholesterol, triglyceride, LDL-cholesterol) and atherogenic indices (LDL/HDL and Triglyceride/HDL) were significantly $(P \leq 0.001)$ altered in the hypercholesterolemic groups where LDL cholesterol and total cholesterol increased up to seven fold in comparison to the untreated control. Notably, treatment of hypercholesterolemic rabbits with either the pod extract or a standard statin drug resulted in a significant reduction in the lipid profile and atherogenic indices (Figure 3).

\section{Serum antioxidant capacity}

Treatment of rabbits with either atorvastatin or the pod extract resulted in significant $(P \leq 0.001)$ changes in the level of catalase, SOD, GSH, lipid peroxidation, and total antioxidants (Figure 4). SOD, $\mathrm{GSH}$, and catalase levels were significantly decreased in the diabetic control group, while the level of lipid peroxidation (LPO) increased. Total antioxidant levels were also significantly lower in the hypercholesterolemic control rabbits, relative to the untreated control rabbits. Treatment of the 
hypercholesterolemic rabbits with a standard, statin drug or pod extract resulted in significantly alleviated levels of catalase, SOD, GSH, and total antioxidant levels, relative to the levels in hypercholesterolemic rabbits. The level of LPO was also significantly decreased in treatment groups (Figure 4).

\section{Histopathology and planimetric study of aorta}

The histoarchitecture of the aorta in untreated, control rabbits exhibited normal layered wall structure with intima, media and adventitia, and a normal lumen volume (Figure 5A). In contrast, the aorta of hypercholesterolemic rabbits exhibited increased thickness in their intima and media, as well as bulging depositions of fatty substances and the presence of foam cells and a fatty band of atherosclerotic plaque. The normal layering of the aorta cell wall was absent, and the lumen volume was decreased (Figure 5B). Treatment of hypercholesterolemic rabbits with Atorvastatin or pod extract resulted in a significant reduction in plaque area, intima, and total volume. Consequently, the lumen volume of the aorta increased significantly in the treated rabbits (Figure 5C \& 5D; Figure 6).

\section{In-silico Studies}

\section{Molecular docking}

The docking was successfully accomplished, and the best conformation of each ligand was determined based on its binding to HMG-COA reductase. More negative $\Delta \mathrm{G}$ values indicate stronger binding to the receptor. The top three binding molecules, based on the glide score, were cloprostenol, cinecromen, and dirithromycin with glide scores of $-5.923,-4.625$, and -4.289 , respectively. The score of the hydrogen bond interactions of the compounds with amino acids are listed in Table 1. The docked pose, indicating the hydrogen bonds and the $\mathrm{H}$-bond distances of cloprostenol, cinecromen, and dirithromycin are shown in Figure 7A, 7B, and 7C, as well as in Table 1. Atorvastatin and Pravastatin were used as positive controls in in-vivo and in vitro assessments, respectively (Table 1).

\section{Pharmacokinetic analysis}

The pharmacokinetic analysis conducted to evaluate the ADMET properties of the identified compounds for their potential use as pharmaceutical drugs indicated that they conformed to the Lipinski rule of five, except for cinecromen, lupeol, and ophiobolene (Table 2). Cinecromen violated the rule as its molecular weight is above $500 \mathrm{~g} / \mathrm{mol}$ and it possesses 13 potential hydrogen acceptor groups. Cloprostenol conformed to the Lipinski rules for an ideal drug compound but was found to be unable to cross the BBB since it possesses an acidic group in its structure. Cinene, cineole, prosogan, and prosolanapynone II were all identified to be suitable drug candidates based on their ADMET properties and because they conformed to the Lipinski rules, along with their ability to cross the BBB.

\section{Phytochemistry of the pod extract}

LC-MS/MS, GC-MS/MS results and the METLINE mass hunter software indicated the presence of 17 bioactive compounds with cloprostenol, cinecromen, and dirithromycin being the most dominant (Table 2, 
Figures $8 \mathrm{~A}, 8 \mathrm{~B}, 8 \mathrm{C}$, and $8 \mathrm{D})$.

The presence of different functional groups in the test extract through FTIR $(\mathrm{N}-\mathrm{H}, \mathrm{CH}$ and $\mathrm{O}-\mathrm{H}$ to $\mathrm{N}-\mathrm{H}, \mathrm{OH}$ and $\mathrm{O}-\mathrm{H}, \mathrm{C}-\mathrm{Br}$ ) were observed in the obtained spectra in the range of 3821.04 to 678.43 (Table 4, Figure $8 \mathrm{E})$.

\section{Discussion}

Hypercholesterolemia and atherosclerosis are associated with dysregulation of the cholesterol biosynthetic pathway and further consequent events [40].The present study determined the effectiveness of an aqueous pod extract of Prosopis cineraria (L.) Druce as an anti-atherosclerotic plaque and antihypercholesterolemia agent as evidenced by its ability to inhibit $\backslash$ HMG-CoA reductase activity, and enhance antioxidant capacity in hypercholesterolemic rabbits. The statins (HMG-CoA reductase) have been established to restore endothelial function by several mechanisms, comprising promoting endothelial NO synthase (eNOS) protein expression and subsiding formation of reactive oxygen species[41]. Accordingly, the statins alter membrane microdomain formation, resulting in reduced expression of proteins that specifically inhibit eNOS activation. Afterward, the statins reduce sterol biosynthesis, hence interfering with the development of pathologic microdomains, including cholesterol crystalline structures. Consequently, the statins improve endothelial function by interfering with oxidative stress pathways through both enzymatic and nonenzymatic mechanisms. It is well recognized reported about the relationships between membrane microdomains, cholesterol biosynthesis, and endothelial function by several studies[41, 42]. Hypercholesterolemia was induced in the test rabbits by administering oral supplements of cholesterol in conjunction with a high fat diet, together which results in altering the cholesterol biosynthetic pathway through its impact on HMG-CoA reductase activity and creating an imbalance in the level of free radicals [43-45]. Accordingly, it was reported that Cholesterol is derived from the diet and from de novo synthesis by increased SREBP-2 expression which upregulates HMG-CoA reductase leading to elevated cholesterol biosynthesis in the liver. Elevated levels of total cholesterol, LDL, and other atherogenic indices indicated that the inducing treatment adversely affected the regulation of the negative feedback control of cholesterol biosynthesis[46]. Consequently, decreased levels of catalase, GSH, SOD, as well as increased lipid peroxidation were observed in the rabbits with hypercholesterolemia. These collective effects promoted the progression of atherosclerosis by initiating endothelial dysfunction [47-49]. The formation of atherogenic plaque was also observed in the hypercholesterolemic rabbits which may be the result of endothelial dysfunction due to high levels of free radicals, trapping of fatloaded macrophages, and fatty streak formation. Further progression of atherosclerosis may have been due to incomplete oxidation of deposited fatty substance in the arterial walls[50-52]. Similar alterations were observed in a study of the effect of capsaicin on hypercholesterolemia and atherosclerosis in guinea pigs[53]. Reactive oxygen species (ROS) are known to have an adverse impact on biomolecules, such as proteins, lipids, and nucleic acids, in cells that contribute to the development of numerous chronic health disorders such as diabetes, metabolic syndrome, cardiovascular disease and even cancer[54]. In the present study, the administration of aqueous pod extracts of Prosopis cineraria and the standard statin drug, atorvastatin, resulted in significant reductions in the lipid profile and atherogenic 
indices in hypercholesterolemic rabbits. This effect may be partially due to the ability of the pod extract (and the statin drug) to inhibit HMG-CoA reductase, which is a key enzyme in cholesterol biosynthesis[44]. This premise was validated by the significant interactions observed between HMG-CoA reductase and several phytoconstituents present in the pod extract in the molecular docking analysis[55]. The main phytoconstituents identified in the pod extract were cloprostenol, cinecromen, and dirithromycin; all of which showed significant molecular interaction with HMG-CoA reductase in the docking studies. Similar interactions between enzymatic targets and other natural phytoconstituents has been previously documented $[55,56]$. Administration of the pod extract also caused a regression in the amount of atherosclerotic plaque and in the thickness of the aortal wall in hypercholesterolemic rabbits. Increased lumen volume was also observed in diseased rabbits treated with the pod extract which may have been due to the depletion of deposited fatty substances and increased oxidation of deposited fats as reported in earlier studies $[8,57-60]$. Oxidative stress results from the excessive generation of free radicals in cells and leads to a number of metabolic disorders that affect the quality of life. Plants are known to possess a variety of different secondary metabolites that exhibit strong antioxidant (REF). Inclusion of these plants and/or their phytoconstituents in the human diet can prevent oxidative stress in cells and tissues and help to maintain normal physiology $[61,62]$. Different phytoconstituents have varying levels of antioxidant capacity and these secondary metabolites should be considered a valuable resource in human diets as reported in several ancient medical systems [63, 64].

Treatment of hypercholesterolemic rabbits with pod extract resulted in a significant increase in the level of catalase, SOD, GSH, a decrease in lipid peroxidation, and an increase in the total antioxidant capacity in blood serum. These changes boosted the free radical scavenging capacity in the body and was most likely induced by the phytoconstituents present in the pod extract and the atorvastatin in a similar manner reported in previous studies $[8,45,65]$. The free radical scavenging capacity of the phytoconstituents present in the pod extract was evaluated in in-vitro assays, including FRAP, TEAC, and ABTS. The free radical scavenging properties of the phytoconstituents may be due the existence of active functional groups as revealed by FTIR analysis[66]. The synthesis of these secondary metabolites in pods and plants of $P$ cineraria may be induced by the adverse desert climate condition present in the locations in which $P$. cineraria naturally grows [67]. The identification of small molecular weight compounds present in the pod extracts of $P$. cineraria was also revealed by LC-MS/MS and GC-MS/MS analyses. The in silico ADMET analysis predicted the potential of different phytoconstituents present in the pod extract to have the ability to cross the blood brain barrier, although in vivo assays are required to validate these results.

\section{Conclusion}

Phytoconstituents of an aqueous pod extract of Prosopis cineraria have the potential to attenuate the formation of atherosclerotic plaque and reduce hypercholesterolemia by enhancing free radical scavenging and inhibiting HMG-CoA reductase activity. The study may be validating the traditional uses of pod of Prosopis cineraria as potent ethnomedical food supplement. 


\section{Declarations}

\section{Consent for Publication}

The consent for publication was taken from all the team members and IAEC (Institutional Animal Ethical Committee).

\section{Availability of data and materials}

The data of study have already been incorporated in the manuscript.

\section{Ethics approval and consent to participate}

The current study has key part of animal experimentations for in-vivo study which was already approved by the Institutional Animal Ethics Committee (IAEC), department of Zoology, Jai Narain Vyas University, Jodhpur (Rajasthan)-342001, India is registered under CPCSEA (Reg. No.1646/GO/a/12/CPCSEA valid up to 27.03 .23$)$.

\section{Funding}

The study was not supported by any kind of specific research grants.

\section{Authors contributions}

HR, BPS \&SK - Designing experimental protocols, drafting and review of the manuscript; NJ, HR\& PK conducted in-vivo studies; JKC- conducted the in-vitro analysis of HMG-CoA reductase activity; PK\&ADconducted the in-silico study; PK \& SK - conducted the phytochemical analysis; AH, AAA, EFA - Editing and review the manuscript.

\section{Acknowledgements}

The authors sincerely acknowledge the support of ILS (Institute of Life Sciences), Bhubaneshwar, Odisha for the in-silico analysis. The authors would like to extend their sincere appreciation to the Researchers Supporting Project Number (RSP-2020/134), King Saud University, Riyadh, Saudi Arabia.

\section{Conflict of interest}

No conflicts of interest are present for the authors who conducted this study.

\section{References}

1. Tabares-Guevara JH, Lara-Guzmán OJ, Londoño-Londoño JA, Sierra JA, León-Varela YM, ÁlvarezQuintero RM, et al. Natural biflavonoids modulate macrophage-oxidized LDL interaction in vitro and promote atheroprotection in vivo. Front Immunol. 2017;8(923):1-17. 
2. Ramkumar S, Raghunath A, Raghunath S. Statin therapy: Review of safety and potential side effects. Acta Cardiol Sin. 2016;32:631-9.

3. Nguyen HTL, Panyoyai N, Kasapis S, Pang E, Mantri N. Honey and its role in relieving multiple facets of atherosclerosis. Nutrients. 2019;11:1-22.

4. Tanwar A, Zaidi AA, Bhardwaj M, Rathore A, Chakotiya AS, Sharma N, et al. Herbal informatics approach for the selection of natural compounds targeting diabetes mellitus. Indian J Tradit Knowl. 2018;17:270-5.

5. Yin J, Zhang H, Ye J. Traditional chinese medicine in treatment of metabolic syndrome. Endocr Metab Immune Disord Drug Targets. 2008;8:99-111.

6. Moss JWE, Ramji DP. Nutraceutical therapies for atherosclerosis. Nat Rev Cardiol. 2016;13:513-32.

7. Patil BS, Jayaprakasha GK, Chidambara Murthy KN, Vikram A. Bioactive compounds: Historical perspectives, opportunities and challenges. J Agric Food Chem. 2009;57:8142-60.

8. Prasad K. Regression of hypercholesterolemic atherosclerosis in rabbits by secoisolariciresinol diglucoside isolated from flaxseed. Atherosclerosis. 2008;197:34-42.

9. Modak M, Dixit P, Londhe J, Ghaskadbi S, Paul a DT. Indian herbs and herbal drugs used for the treatment of diabetes. J Clin Biochem Nutr. 2007;40:163-73.

10. Toledo-lbelles P, Mas-Oliva J. Antioxidants in the Fight Against Atherosclerosis: Is This a Dead End? Curr Atheroscler Rep. Current Atherosclerosis Reports. 2018;20:1-12.

11. Diaf M, Khaled MB. Associations Between Dietary Antioxidant Intake and Markers of Atherosclerosis in Middle-Aged Women From North-Western Algeria. Front Nutr. 2018;5:1-8.

12. Forni C, Facchiano F, Bartoli M, Pieretti S, Facchiano A, D'Arcangelo D, et al. Beneficial role of phytochemicals on oxidative stress and age-related diseases. Biomed Res Int. 2019;2019:1-16.

13. Zhang YJ, Gan RY, Li S, Zhou Y, Li AN, Xu DP, et al. Antioxidant phytochemicals for the prevention and treatment of chronic diseases. Molecules. 2015. p. 21138-56.

14. Brahmachari G, Basak A, O’Reilly P, Ozed-Williams B, Basak S. Small Molecule Phytocompounds as Promoters of LDL-receptor and PCSK9 Inhibition: Potential Role as Non-statin Based Cardioprotective Agents. Cardioprot Nat Prod. 2017. p. 277-318.

15. Mahmoud AM, Hernández Bautista RJ, Sandhu MA, Hussein OE. Beneficial effects of citrus flavonoids on cardiovascular and metabolic health. Oxid Med Cell Longev. 2019;2019:1-19.

16. Janbaz KH, Haider S, Imran I, Zia-Ul-Haq M, De Martino L, De Feo V, et al. Pharmacological evaluation of Prosopis cineraria (L.) Druce in gastrointestinal, respiratory, and vascular disorders. Front Pharmacol. 2012;2012:1-7.

17. Kumar L, Prasad M, Arya D, Bhagour K. In vitro and in vivo antidiabetic activity of isolated fraction of Prosopis cineraria against streptozotocin-induced experimental diabetes: A mechanistic study. Biomed Pharmacother. 2018;108:1015-21.

18. Khokar A, Menghani E. Antimicrobial activity of Prosopis cineraria (Leaf) methanol and chloroform extract against selected bacterial species. Int J Pharma Bio Sci. 2015;6(3):B222-9. 
19. Zhu ZJ, Schultz AW, Wang J, Johnson CH, Yannone SM, Patti GJ, et al. Liquid chromatography quadrupole time-of-flight mass spectrometry characterization of metabolites guided by the METLIN database. Nat Protoc. 2013;8:451-60.

20. Baskaran G, Salvamani S, Ahmad SA, Shaharuddin NA, Pattiram PD, Shukor MY. HMG-CoA reductase inhibitory activity and phytocomponent investigation of Basella alba leaf extract as a treatment for hypercholesterolemia. Drug Des Devel Ther. 2015;9:509-17.

21. Keskes H, Belhadj S, Jlail L, El Feki A, Damak M, Sayadi S, et al. LC-MS-MS and GC-MS analyses of biologically active extracts and fractions from tunisian Juniperus phoenice leaves. Pharm Biol. 2017;55:88-95.

22. Lingegowsa DSC, Kumar K, Prasad AGD, Zarei MGS. FTIR spectroscopic studies on Cleome gynandra - Comparative analysis of functional group before and after extraction. Rom J Biophys. 2013;22:137-43.

23. Ergin G, Çag̈lar S, Önal A, Toker SE. Spectrophotometric determination of 3-hydroxy-3-methylglutaryl coenzyme-A reductase inhibitors in pharmaceutical preparations. Turkish J Chem. 2013;37:171-81.

24. Weydert CJ, Cullen JJ. Measurement of superoxide dismutase, catalase and glutathione peroxidase in cultured cells and tissue. Nat Protoc. 2010;5:51-66.

25. Ram H, Jatwa R, Purohit A. Antiatherosclerotic and cardioprotective potential of acacia senegal seeds in diet-induced atherosclerosis in rabbits. Biochem Res Int. 2014;2014:1-9.

26. Abel LL, Levy BB, Brodie BB, Kendall FE. A simplified method for the estimation of total cholesterol in serum and demonstration of its specificity. J Biol Chem. 1952;195:357-66.

27. Klotzsch SG, McNamara JR. Triglyceride measurements: A review of methods and interferences. Clin Chem. 1990;36:1605-13.

28. Hirano T, Nohtomi K, Koba S, Muroi A, Ito Y. A simple and precise method for measuring HDLcholesterol subfractions by a single precipitation followed by homogenous HDL-cholesterol assay. J Lipid Res. 2008;49:1130-6.

29. Trinder P. Determination of blood glucose using an oxidase-peroxidase system with a noncarcinogenic chromogen. J Clin Pathol. 1969;22:158-61.

30. Lowry OH, Rosebrough NJ, Farr ALRR. Protein measurement with folin phenol reagent. J Biol Chem. 1951;193:265-75.

31. Vujovic A, Kotur-Stevuljevic J, Spasic S, Bujisic N, Martinovic J, Vujovic M, et al. Evaluation of different formulas for LDL-C calculation. Lipids Health Dis. 2010;9:1-9.

32. Dobiášová M. Atherogenic index of plasma [log(triglycerides/HDL-cholesterol)]: Theoretical and practical implications. Clin Chem. 2004;50:1113-5.

33. Beauchamp C, Fridovich I. Superoxide dismutase - Improved assays and an assay applicable to acrylamide gels. Anal Biochem. 1971;44:276-87.

34. Rahman I, Kode A, Biswas SK. Assay for quantitative determination of glutathione and glutathione disulfide levels using enzymatic recycling method. Nat Protoc. 2007;1:3159-65. 
35. Buege JA, Aust SD. Microsomal lipid peroxidation. Methods Enzymol. 1978;52:302-10.

36. Benzie IFF, Strain JJ. The ferric reducing ability of plasma (FRAP) as a measure of "'Antioxidant Power"': The FRAP Assay. Anal Biochem. 1996;239:7-76.

37. Peasari J, Motamarry S, sri, Varma KS, Anitha P, Potti RB. Chromatographic analysis of phytochemicals in Costus igneus and computational studies of flavonoids. Informatics Med. 2018;13:34-40.

38. Jasmine JM, Vanaja R. In silico analysis of phytochemical compounds for optimizing the inhibitors of HMG CoA reductase. J Appl Pharm Sci. 2013;3:43-7.

39. Assaad HI, Zhou L, Carroll RJ, Wu G. Rapid publication-ready MS-Word tables for one-way ANOVA. Springerplus. 2014;3:1-8.

40. Prasad K, Lee P. Suppression of hypercholesterolemic atherosclerosis by pentoxifylline and its mechanism. Atherosclerosis. 2007;192:313-22.

41. Mason RP, Walter MF, Jacob RF. Effects of HMG-CoA Reductase Inhibitors on Endothelial Function Role of Microdomains and Oxidative Stress. Circulation. 2004;109:34-41.

42. Rikitake Y, Kawashima S, Takeshita S, Yamashita T, Azumi H, Yasuhara M, et al. Anti-oxidative properties of fluvastatin, an HMG-CoA reductase inhibitor, contribute to prevention of atherosclerosis in cholesterol-fed rabbits. Atherosclerosis. 2001;154:87-96.

43. Wu N, Sarna LK, Hwang SY, Zhu Q, Wang P, Siow YL, et al. Activation of 3-hydroxy-3-methylglutaryl coenzyme A (HMG-COA) reductase during high fat diet feeding. Biochim Biophys Acta - Mol Basis Dis. 2013;1832:1560-8.

44. Scallen TJ, Sanghvi A. Regulation of three key enzyme in cholesterol metabolism by phosporylation/dephosphorylation. Proc Nat Acad Sci. 1983;80:2477-80.

45. Salvamani S, Gunasekaran B, Shukor MY, Shaharuddin NA, Sabullah MK, Ahmad SA. Anti-HMG-CoA Reductase, Antioxidant, and Anti-Inflammatory Activities of Amaranthus viridis Leaf Extract as a Potential Treatment for Hypercholesterolemia. Evidence-Based Complement Altern Med. 2016;2016:1-10.

46. Wu N, Sarna LK, Hwang S, Zhu Q, Wang P, Siow YL, et al. Activation of 3-hydroxy-3-methylglutaryl coenzyme $A$ (HMG-CoA) reductase during high fat diet feeding $₫$. Biochim Biophys Acta. 2013;1832:1560-8.

47. Hemn HO, Noordin MM, Rahman HS, Hazilawati H, Zuki A, Chartrand MS. Antihypercholesterolemic and antioxidant efficacies of zerumbone on the formation, development, and establishment of atherosclerosis in cholesterol-fed rabbits. Drug Des Devel Ther. 2015;9:4173-208.

48. Heinecke JW. Oxidants and antioxidants in the pathogenesis of atherosclerosis: Implications for the oxidized low density lipoprotein hypothesis. Atherosclerosis. 1998;141:1-15.

49. Purohit A, Ram H. Hypolipidemic and antiatherosclerotic effects of Prosopis cineraria bark extract in experimentally induced hyperlipidemic rabbits. Asian J Pharm Clin Res. 2012;5:106-9. 
50. Yang X, Li Y, Li Y, Ren X, Zhang X, Hu D, et al. Oxidative stress-mediated atherosclerosis: Mechanisms and therapies. Front Physiol. 2017;8:1-16.

51. Singh RB, Shinde SN, Chopra RK, Niaz MA, Thakur AS, Onouchi Z. Effect of coenzyme Q10 on experimental atherosclerosis and chemical composition and quality of atheroma in rabbits. Atherosclerosis. 2000;148:275-82.

52. Daniel S. Atherogenesis in perspective: Hypercholesterolemia and. Nat Med. 2002;8:1211-7.

53. Yang S, Liu L, Meng L, Hu X. Capsaicin is beneficial to hyperlipidemia, oxidative stress, endothelial dysfunction, and atherosclerosis in Guinea pigs fed on a high-fat diet. Chem Biol Interact. 2019;297:1-7.

54. Bandeira S, de M, da Fonseca, Guedes LJS, G da S, Rabelo, Goulart LA, Vasconcelos MOF SML. Oxidative stress as an underlying contributor in the development of chronic complications in diabetes mellitus. Int J Mol Sci. 2013;14:3265-84.

55. Akther S. Insilico Molecular Docking of Some Isolated Selected Compounds of Phoenix Sylvestris (L.) Against Diabetes. Biomed J Sci Tech Res. 2019;16:11883-6.

56. Suganya S, Nandagopal B, Anbarasu A. Natural Inhibitors of HMG-CoA Reductase-An Insilico Approach Through Molecular Docking and Simulation Studies. J Cell Biochem. 2017;118:52-7.

57. Kalanuria $A A$, Nyquist $P$, Ling $G$. The prevention and regression of atherosclerotic plaques: Emerging treatments. Vasc Health Risk Manag. 2012;8:549-61.

58. Páramo JA, Civeira F. Is regression of atherosclerotic plaque possible? Clínica e Investig en Arterioscler (English Ed.). 2017;29:46-50.

59. Feig JE. Regression of Atherosclerosis: Insights from Animal and Clinical Studies. Ann Glob Heal. 2014;71:3831-40.

60. Almeida SO, Budoff M. Effect of statins on atherosclerotic plaque. Trends Cardiovasc Med. 2019;1:9-30.

61. Lee MT, Lin WC, Yu B, Lee TT. Antioxidant capacity of phytochemicals and their potential effects on oxidative status in animals - A review. Asian-Australasian J Anim Sci. 2017;30(3):299-308.

62. Tungmunnithum D, Thongboonyou A, Pholboon A, Yangsabai A. Flavonoids and Other Phenolic Compounds from Medicinal Plants for Pharmaceutical and Medical Aspects: An Overview. Medicines. 2018;5:93.

63. Johar D, Maher A, Aboelmagd O, Hammad A, Morsi M, Warda HF, et al. Whole-food phytochemicals antioxidative potential in alloxan-diabetic rats. Toxicol Reports Elsevier. 2018;5:240-50.

64. Grover JK, Yadav S, Vats V. Medicinal plants of India with anti-diabetic potential. J Ethnopharmacol. 2002;81:81-100.

65. Schneider W, Dalferth P, Kelber O, Friedemann G, Haasis R, Heinle H. Oxidizability of low density lipoprotein and total antioxidative capacity of plasma are differently altered during induction and regression of hypercholesterolemia in rabbits. Atherosclerosis. 1999;144:69-72. 
66. Kumar A, Ramaswamy M. Phytochemical screening by FTIR spectroscopic analysis of leaf extracts of selected Indian Medicinal plants. IntJCurrMicrobiolAppSci. 2014;3:395-406.

67. Ota A, Ulrih NP. An overview of herbal products and secondary metabolites used for management of type two diabetes. Front Pharmacol. 2017;8:1-14.

\section{Figures}

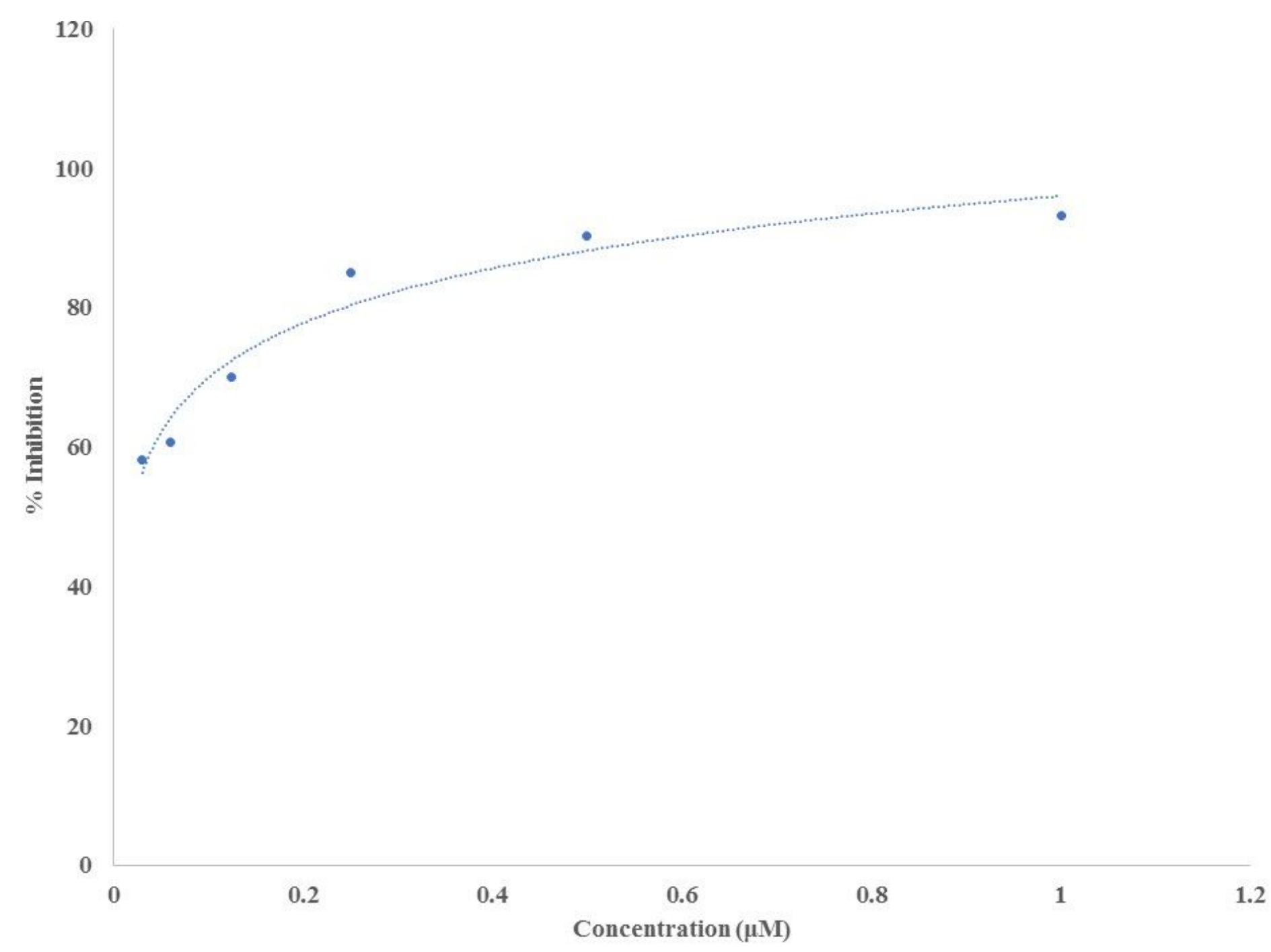

\section{Figure 1}

Concentration dependent HMG - CoA reductase inhibition by Pravastatin (Equation- $y=11.335 \ln (x)+$ 96.013, $\mathrm{R}^{2}=0.9517 ; \mathrm{IC} 50=0.02 \mu \mathrm{M}$ 


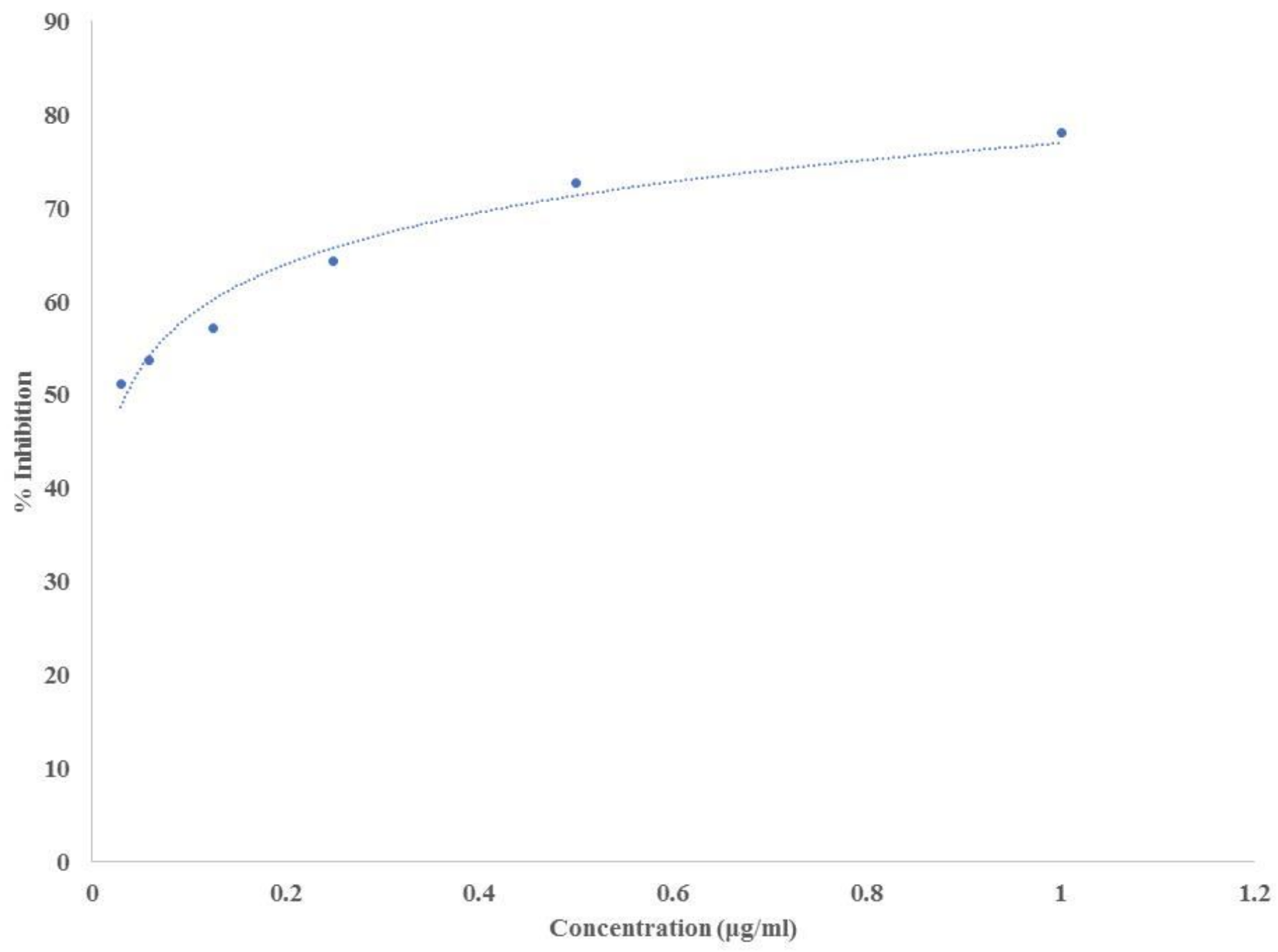

Figure 2

Concentration dependent HMG - CoA reductase inhibition by aqueous pod extract of Prosopis cineraria (L.) Druce (Equation: $y=8.0719, \mathrm{n}(\mathrm{x})+76.947 ; \mathrm{IC} 50=0.03 \mu \mathrm{g} / \mathrm{ml}$ )

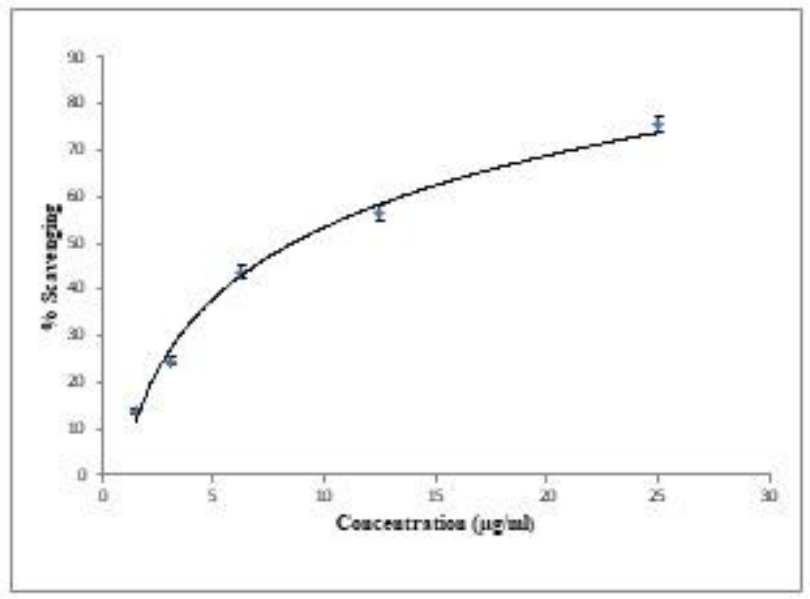

Figure 3 
ABST assessment of antioxidant potential of aqueous pod extract of Prosopis cineraria (L.) Druce.

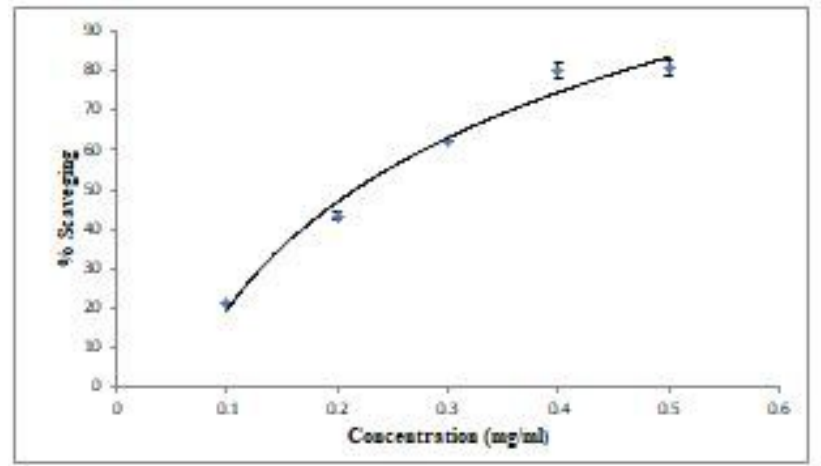

\section{Figure 4}

FRAP assay of total antioxidant potential of aqueous pod extract of Prosopis cineraria (L.) Druce.

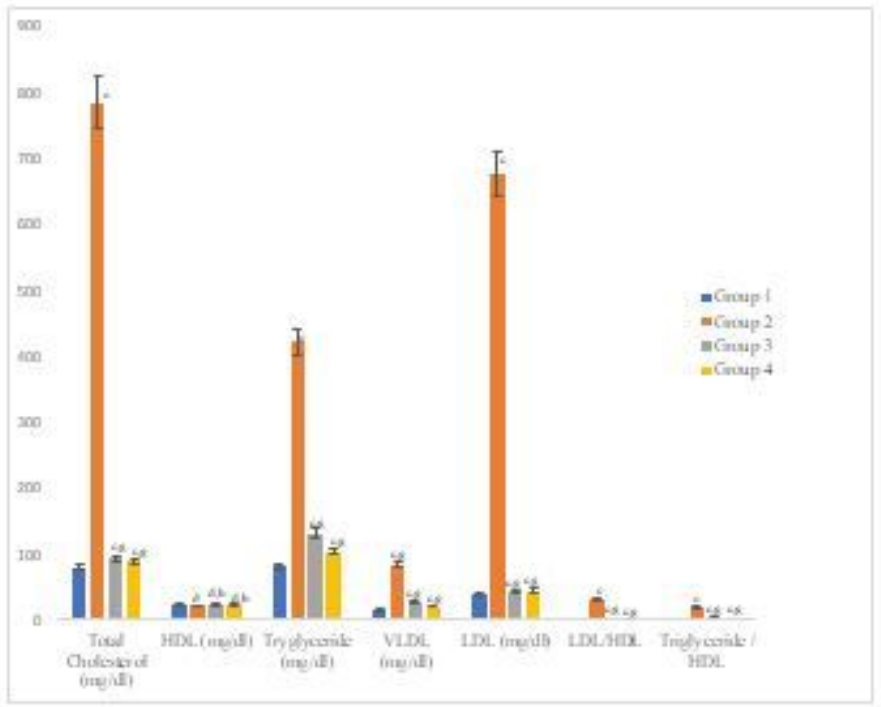

\section{Figure 5}

Lipid profile and atherogenic indices of various treated groups Data are means \pm S.E.M. $(n=5)$; a $P \leq$ 0.05 ; b $P \leq 0.01$; c $P \leq 0.001$; and $d$ was non-significant as compared to the respective control values. e $P \leq 0.05 ; \mathrm{g} P \leq 0.001$; and $\mathrm{h}$ was non-significant as compared to the respective values of the hypercholesterolemic control group. 


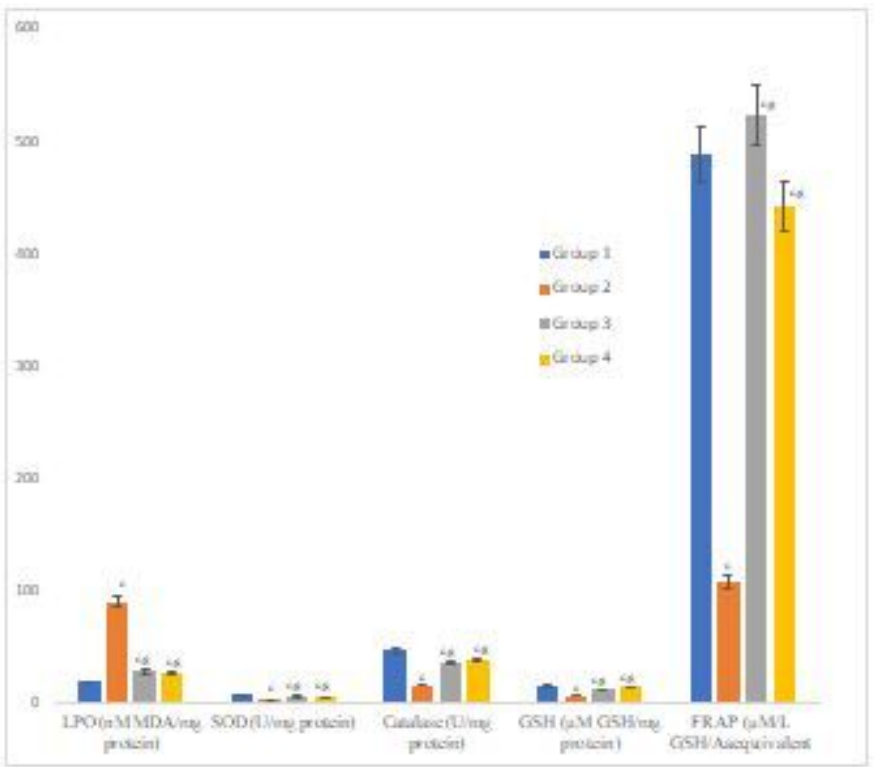

Figure 6

Serum antioxidants status of various treated groups Data are means \pm S.E.M. (n= 5); a $P \leq 0.05$; b $P \leq$ 0.01 ; c $P \leq 0.001$; and $d$ was non-significant as compared to the respective control values. e $P \leq 0.05 ; \mathrm{g}$ $P \leq 0.001$; and $\mathrm{h}$ was non-significant as compared to the respective values of the hypercholesterolemic control group. 


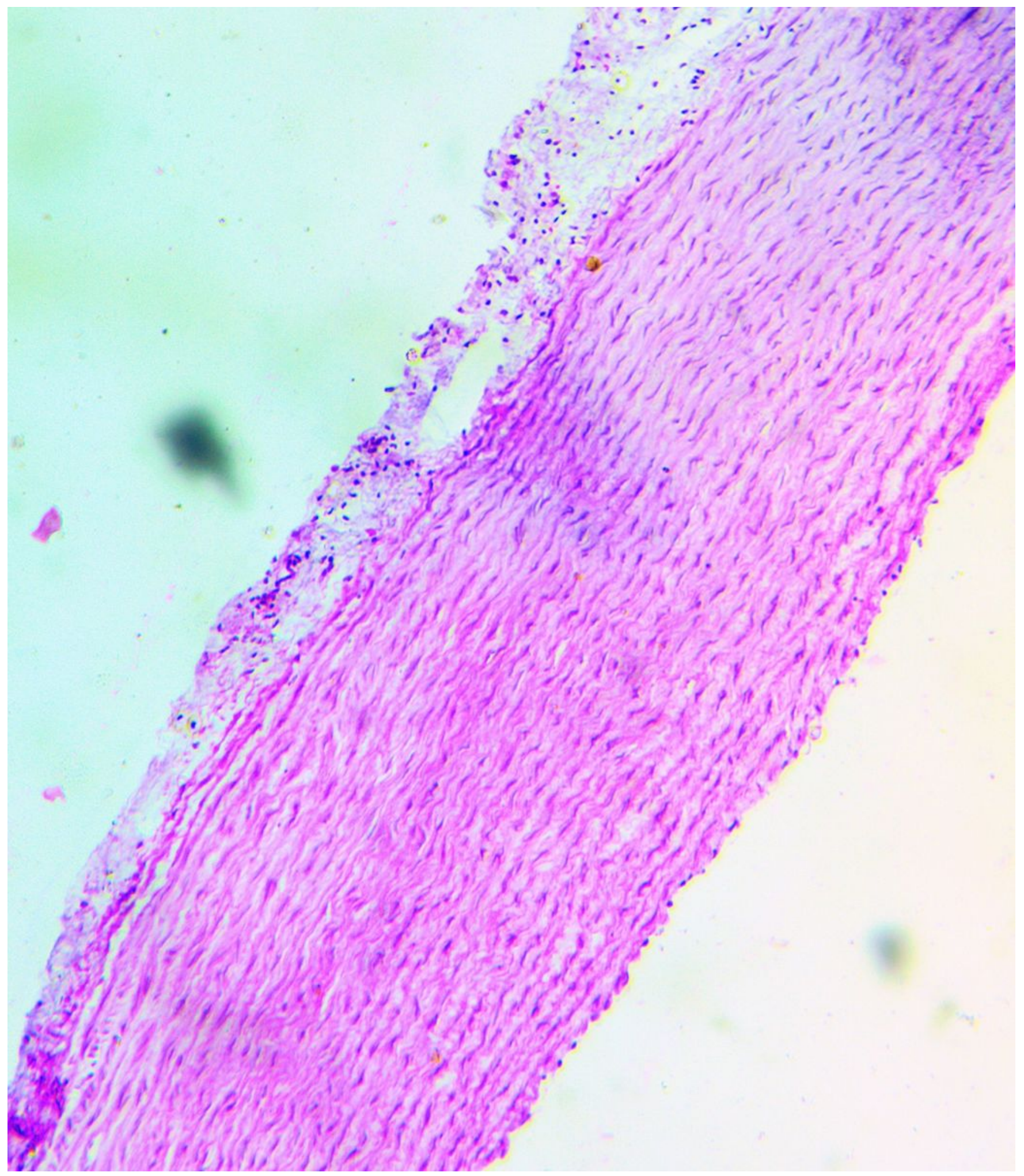

Figure 7

Histology of aorta of intact vehicle control (400x H\&E): Aortal wall exhibiting regular arrangement of intima, media and adventitia. 


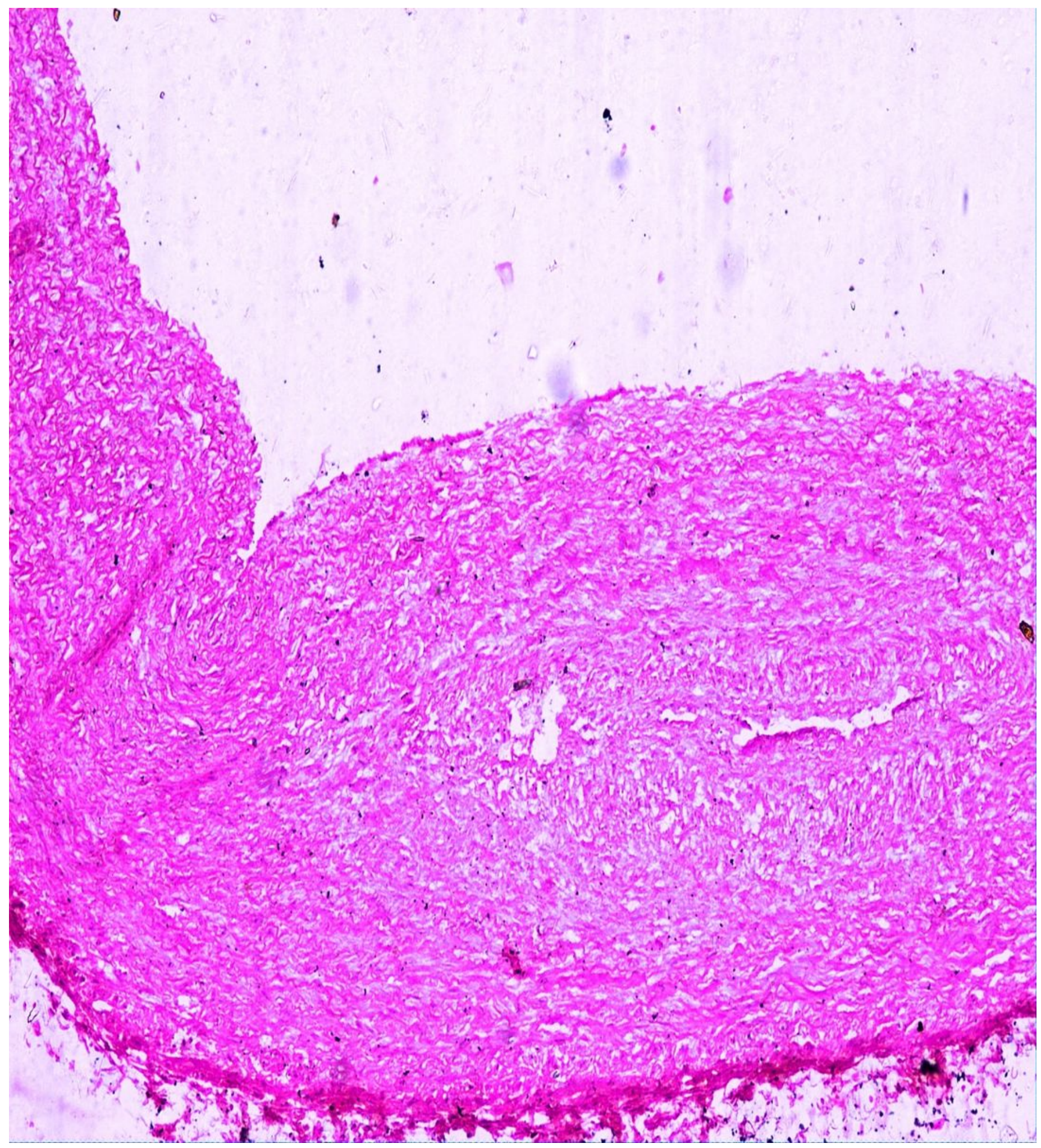

Figure 8

Histology of hypercholesterolemic aorta exhibiting with atherosclerotic plaque (400x H\&E): Arrow indicating the atherosclerotic plaque. 


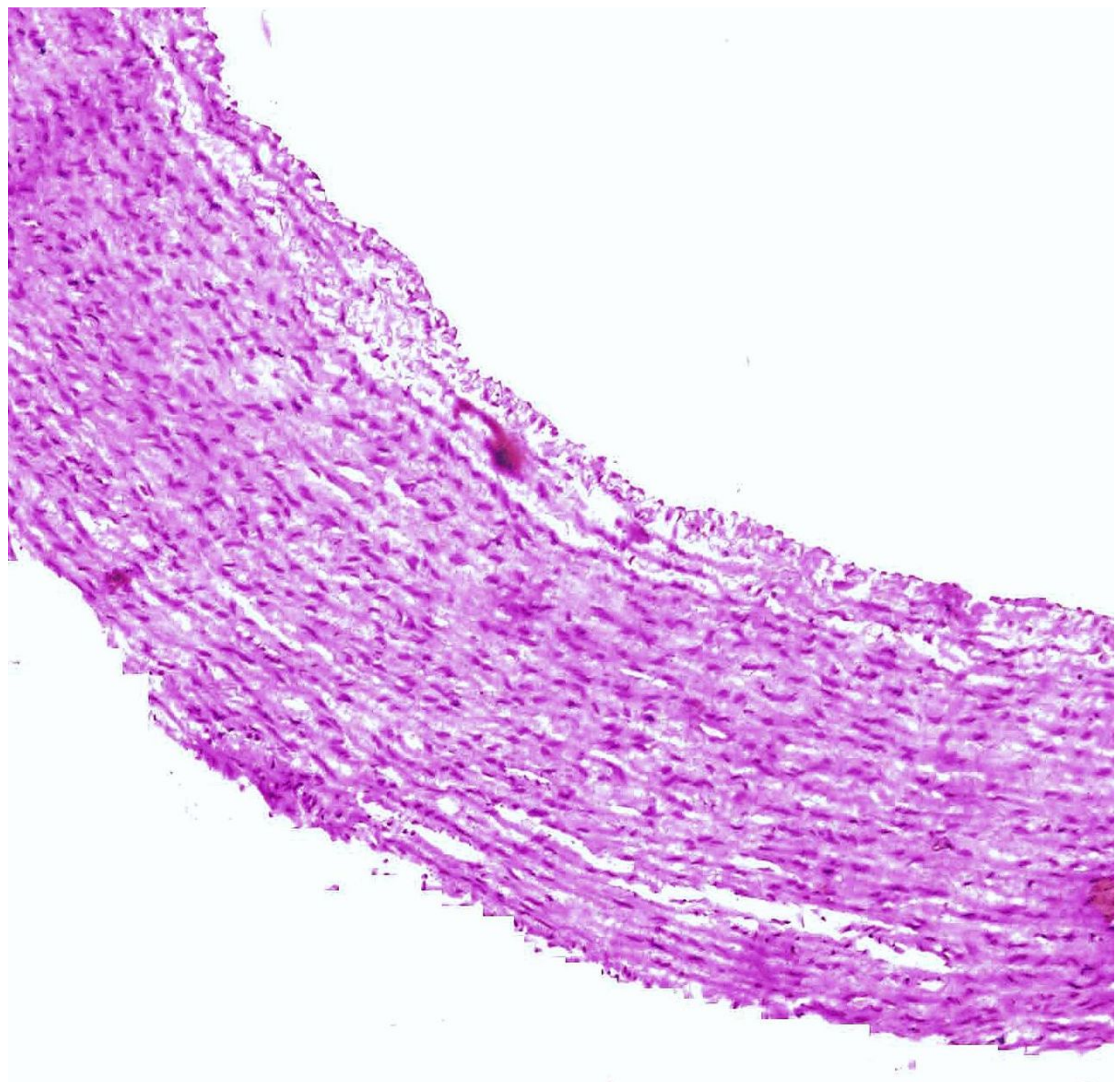

Figure 9

Histology of aqueous pod extract of Prosopis cineraria (L.) Druce. treated aorta (400x H\&E): Arrow indicating regressed atherosclerotic plaque area. 


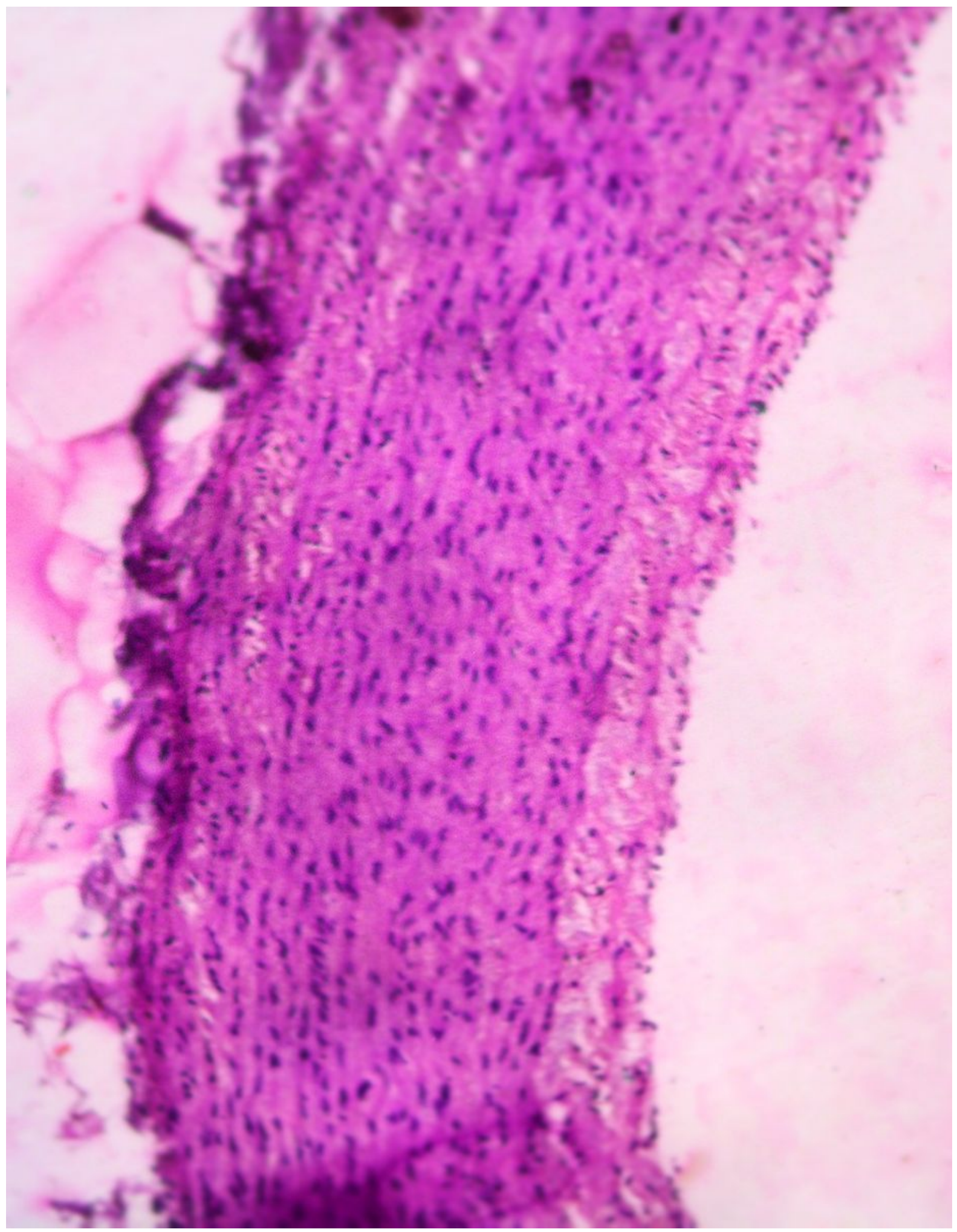

Figure 10

Histology of atorvastatin treated aorta $(400 x \mathrm{H} \& \mathrm{E})$ : Arrow indicating regressed area of atherosclerotic plaque. 


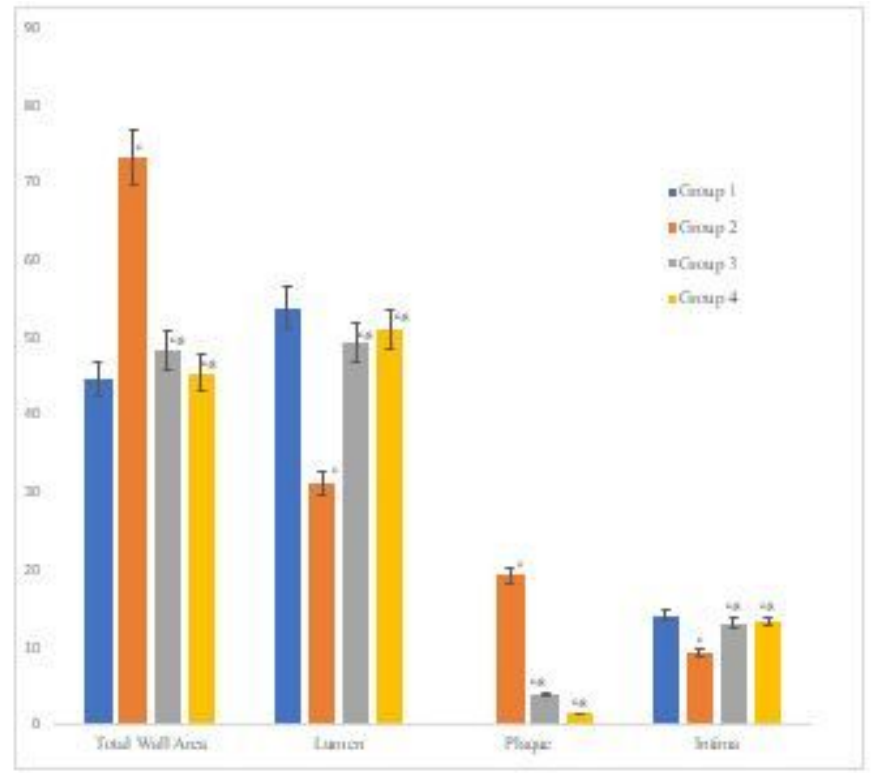

\section{Figure 11}

Aortal wall and plaque regression status in various treated groups Data are means \pm S.E.M. $(n=5)$; a $P \leq$ 0.05 ; b $P \leq 0.01$; c $P \leq 0.001$; and $d$ was non-significant as compared to the respective control values. e $P \leq 0.05 ; \mathrm{g} P \leq 0.001$; and $\mathrm{h}$ was non-significant as compared to the respective values of the hypercholesterolemic control group. 


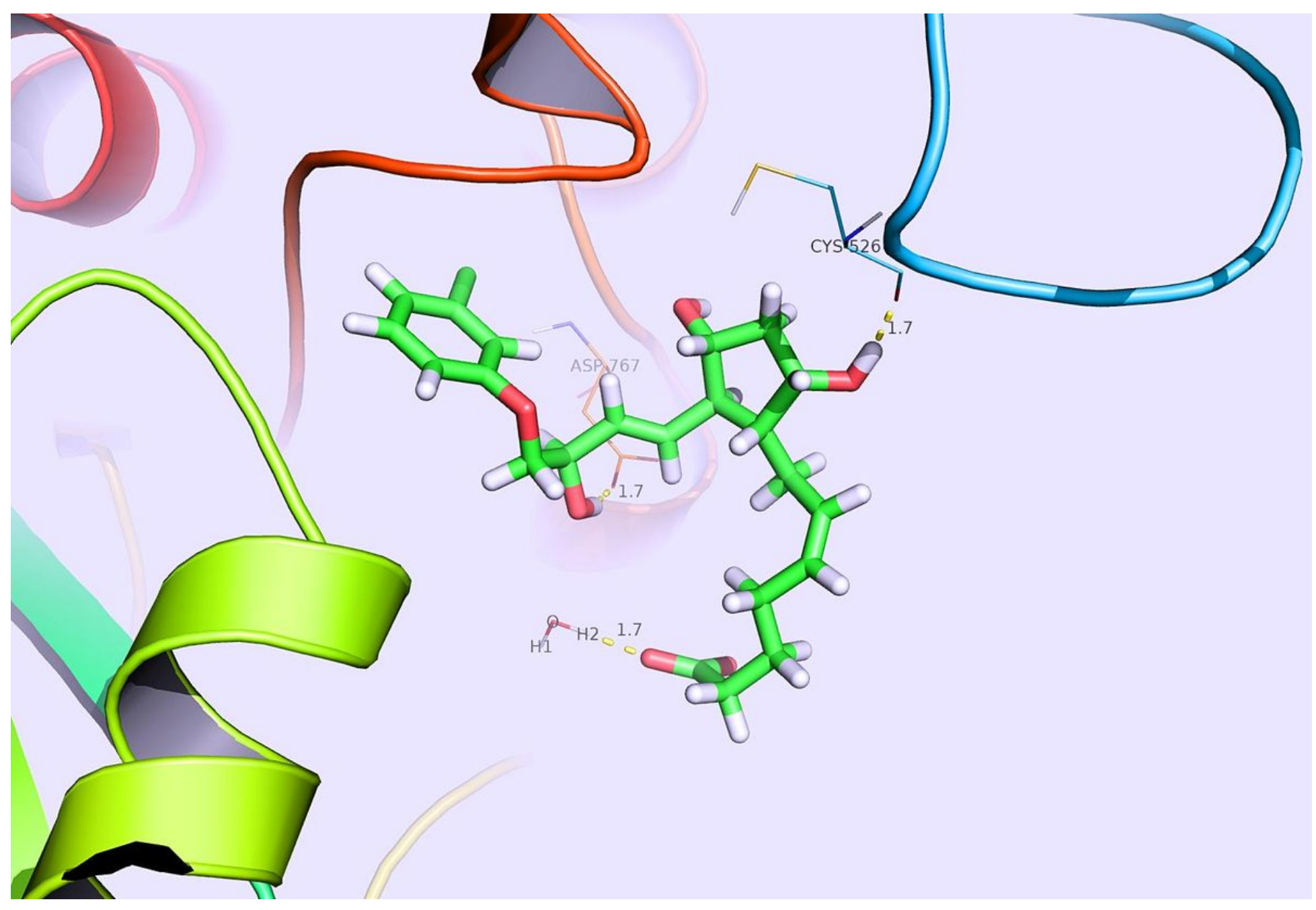

Figure 12

Interaction with target enzyme HMG-CoA and Cloprostenol 


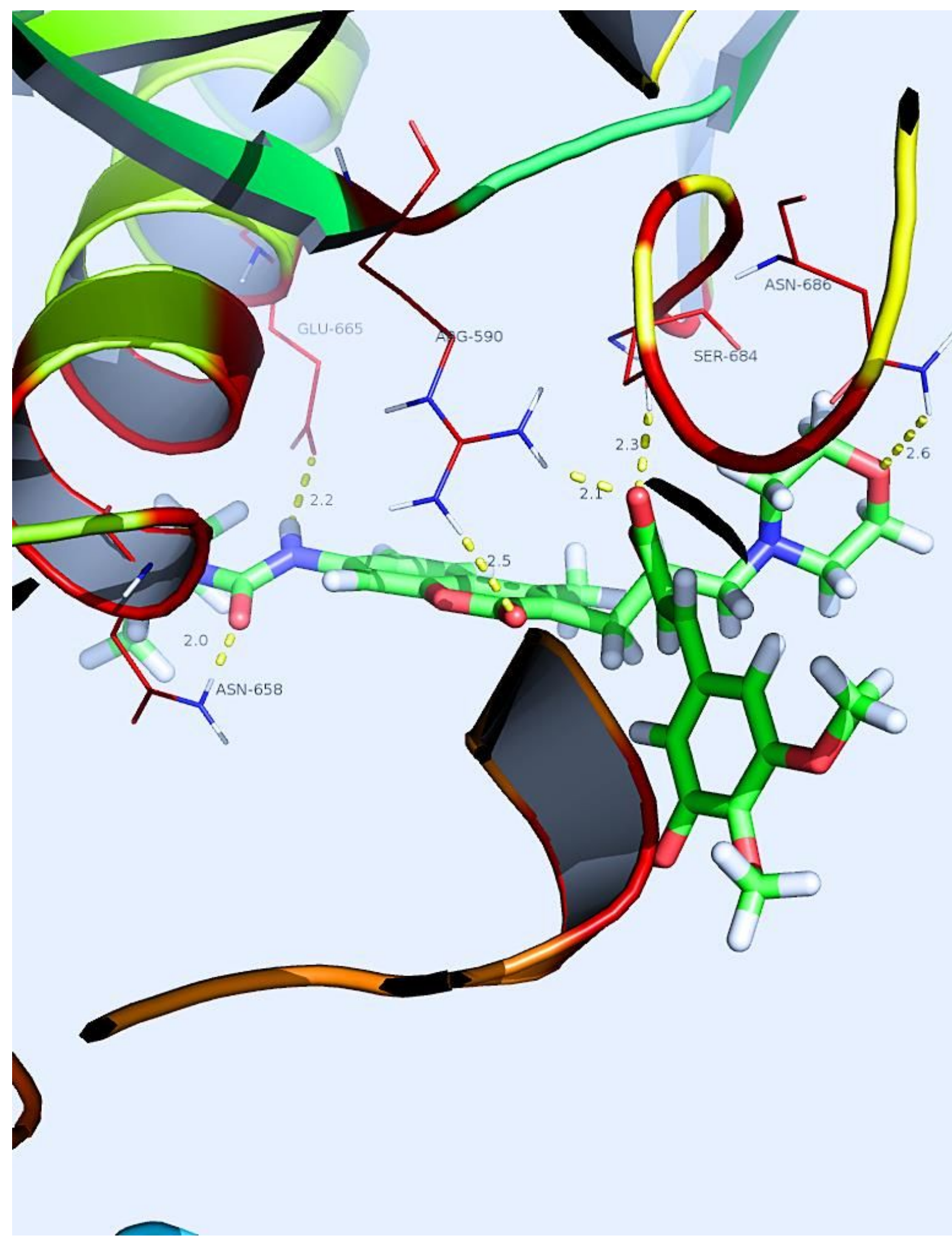

Figure 13

Interaction with target enzyme HMG-CoA and Cinecromen 


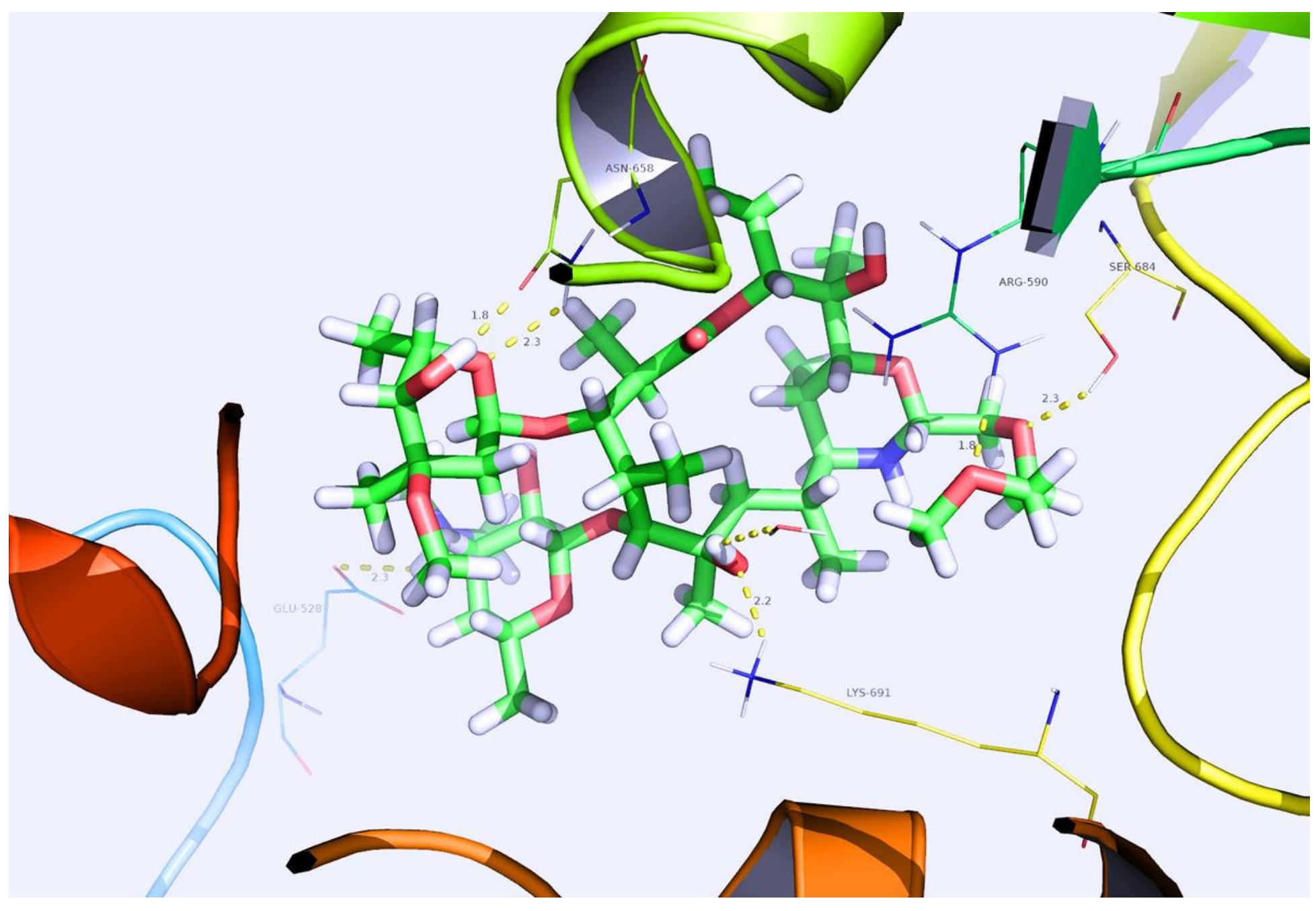

Figure 14

Interaction with target enzyme HMG-CoA and Dirithromycin 


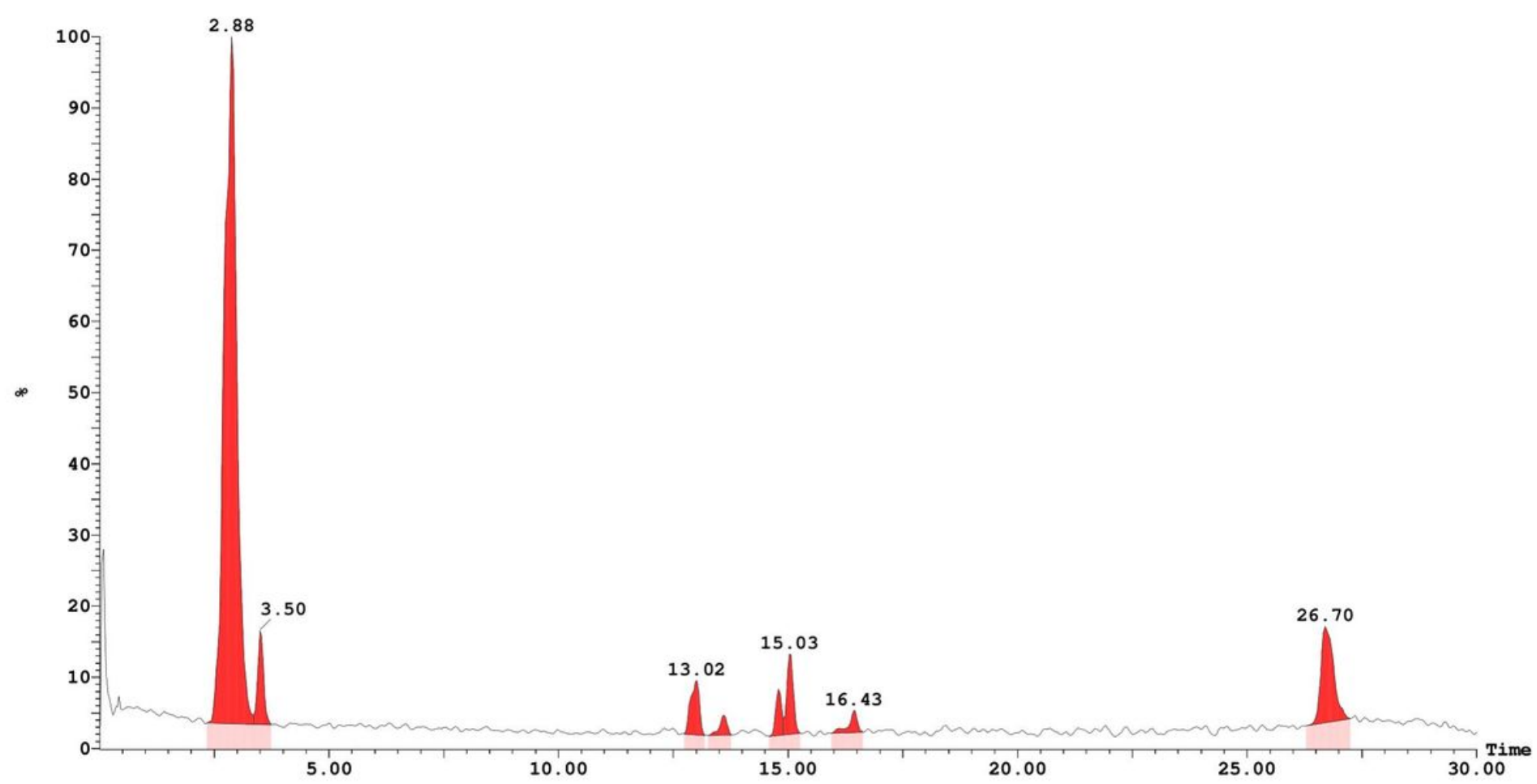

Figure 15

UPLC chromatograph of aqueous pod extract of Prosopis cineraria (L.) Druce

2: MS ES- :BPI

2. $6 \mathrm{e}+006$

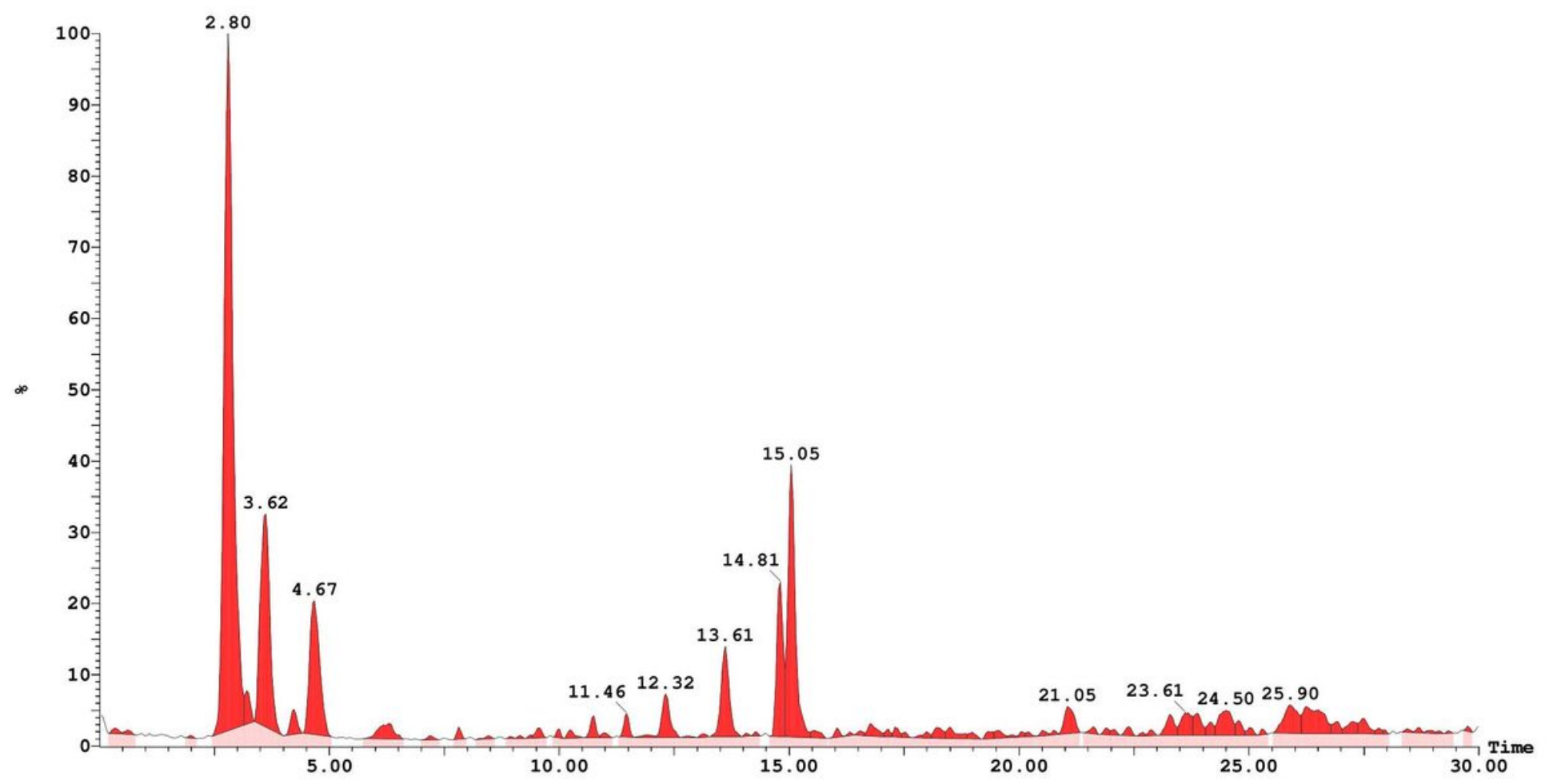

Figure 16 
UPLC chromatograph of aqueous pod extract of Prosopis cineraria (L.) Druce

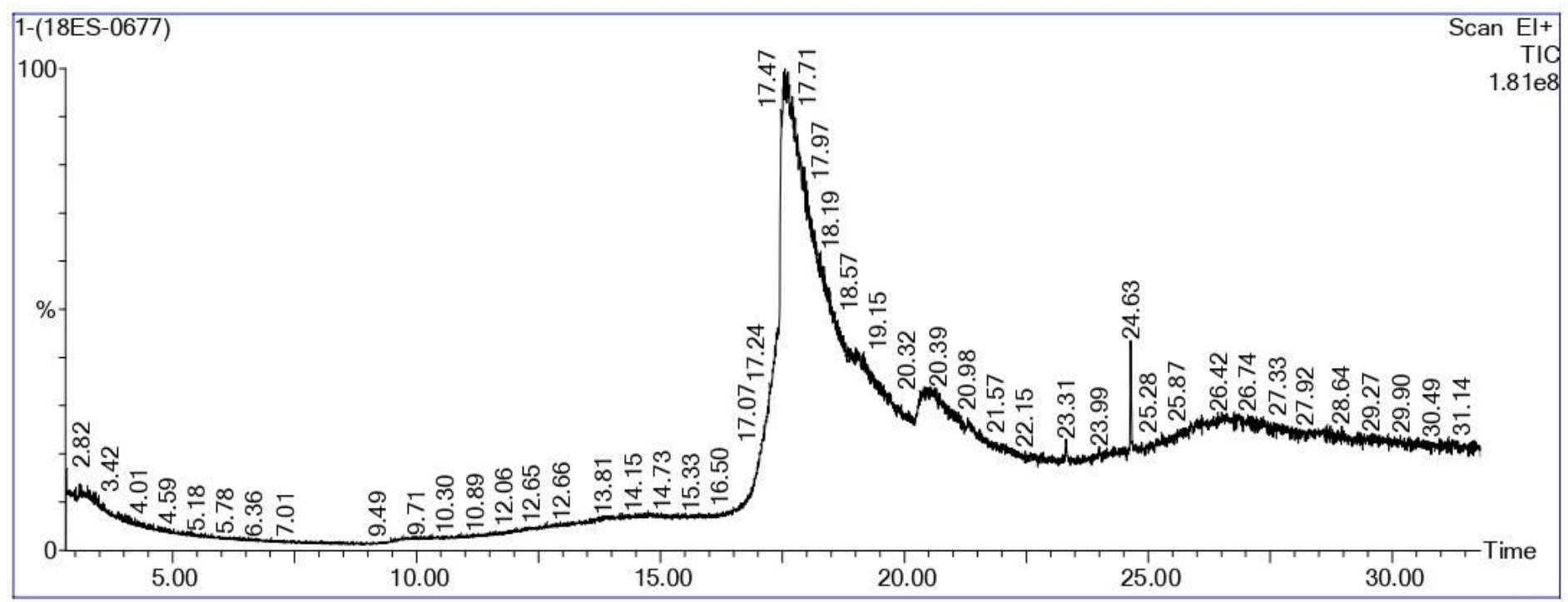

Figure 17

GC-MS analysis of aqueous pod extract of Prosopis cineraria (L.) Druce 


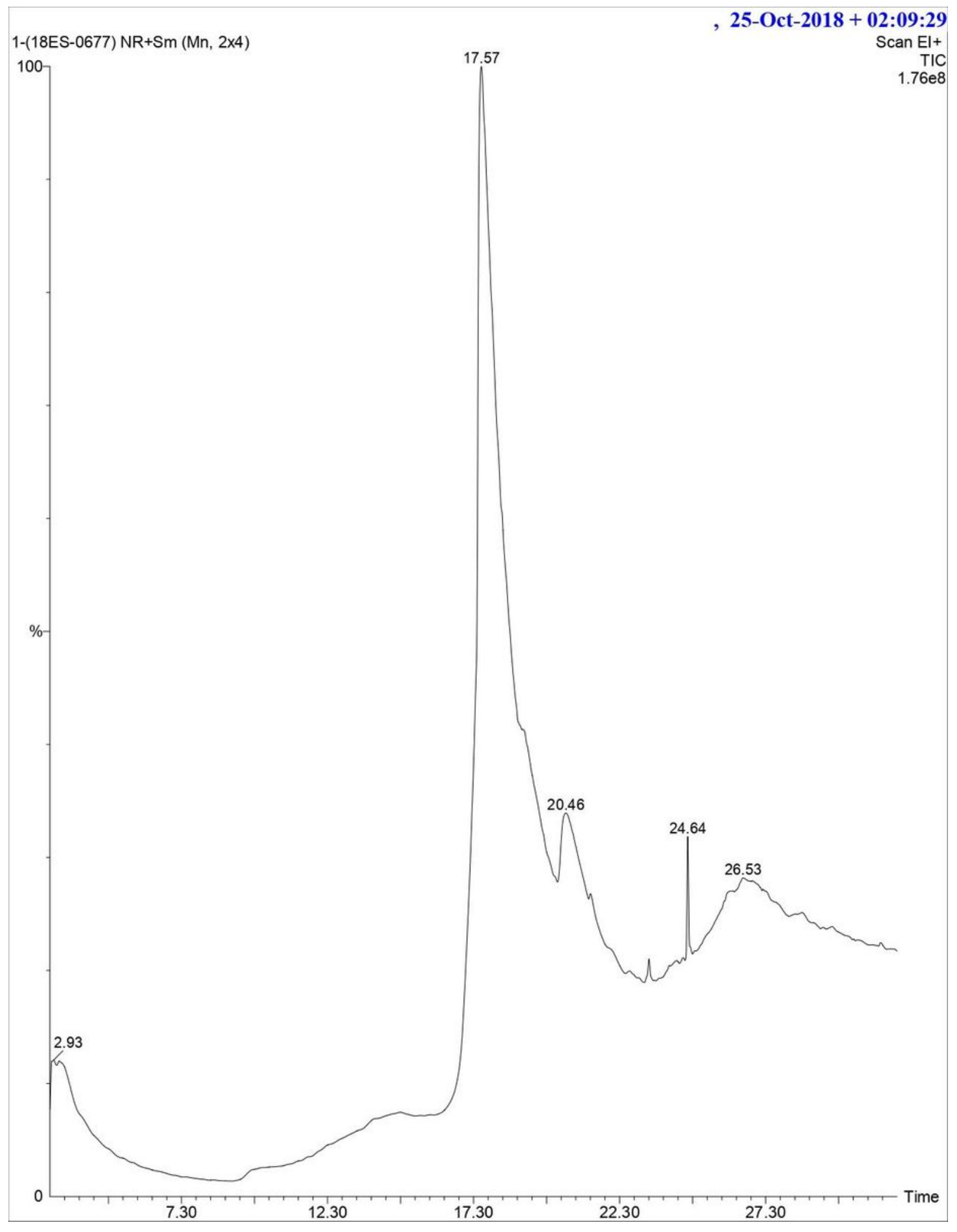

Figure 18

Chromatograph of GC-MS analysis of aqueous pod extract of Prosopis cineraria (L.) Druce 


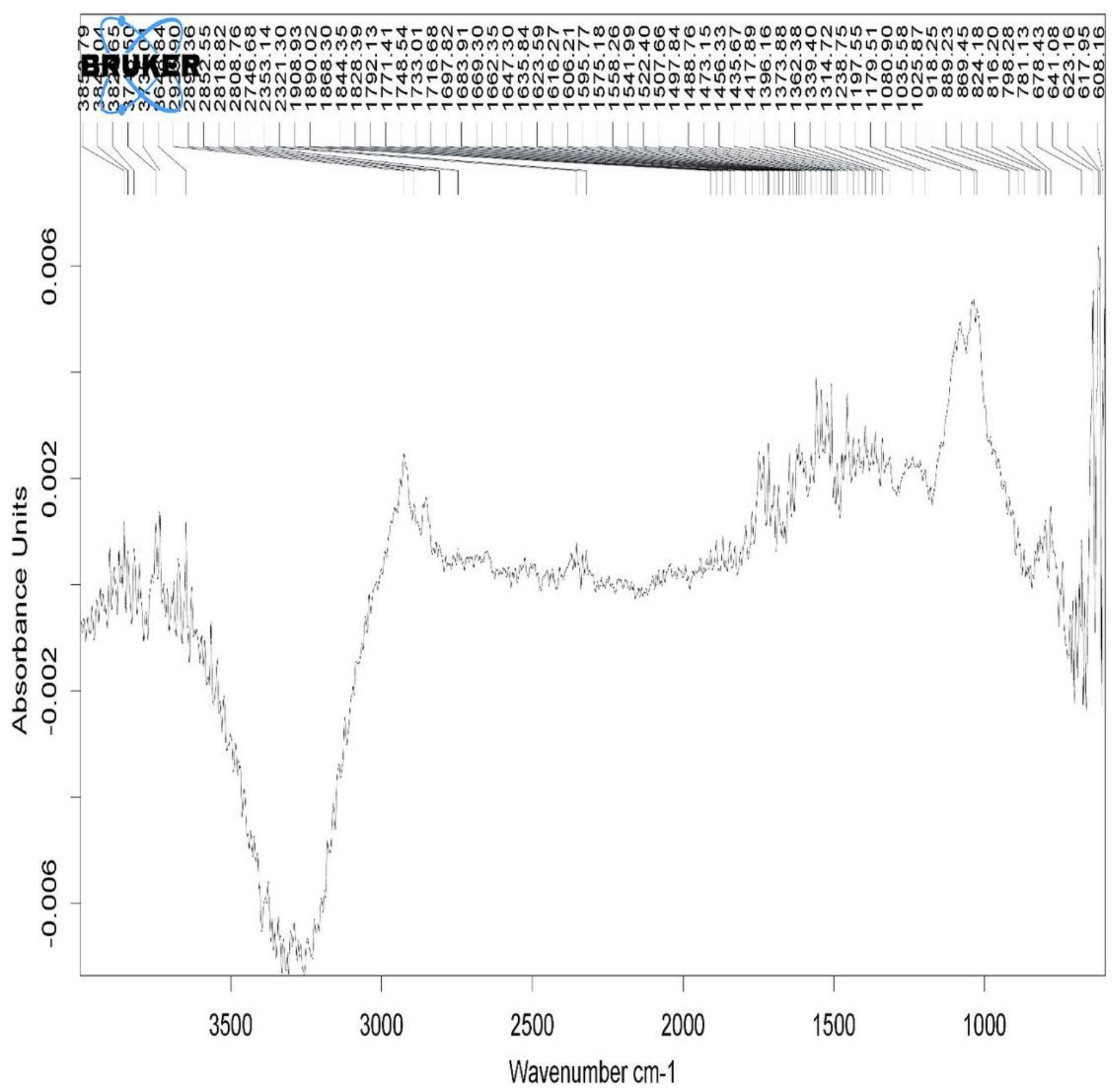

Figure 19

FTIR analysis of aqueous pod extract of Prosopis cineraria (L.) Druce 